\title{
Design and Implementation of Urban Search and Rescue Robot
}

\author{
Md. Moniruzzaman ${ }^{a^{*}}$, Md. Saniat Rahman Zishan ${ }^{a}, S_{\text {Sabbir Rahman }}$, Sanwar Mahmud ${ }^{\mathrm{a}}$, \\ Antar Shaha ${ }^{\mathrm{a}}$
}

\author{
${ }^{a}$ Department of EEE, American International University-Bangladesh, Dhaka-1229, Bangladesh
}

Received: 14 July 2017; Accepted: 08 January 2018; Published: 08 March 2018

\begin{abstract}
Disasters unsettle the economic and social stability of society. Shortage of skilled rescue workforces, as well as the risks involved in search and rescue operations, are becoming foremost problems during an emergency situation. To solve these problems, we have designed and implemented an Urban Search and Rescue (USAR) robot. The robot is designed and implemented in such a way that includes the application of digital electronics, embedded programming, digital signal processing and digital sensors. This USAR robot uses the microcontroller PIC 16F690 to control its movement by using a radio frequency module and PIC 16F73 to collect the sensor's data and transmit the data through Bluetooth module. These are low power and costeffective chips. The PIR sensor, Co2 gas sensor, and temperature sensor will collect the data of the disaster area and transmit the data to the service station. Even though, a camera is operated for visual purpose. In this paper not only we have designed and implemented USAR robot but also we tested and analyzed the result.
\end{abstract}

Index Terms: USAR Robot, Search, Rescue, Disaster, PIR Sensor, Gas Sensor, RF Module, Bluetooth.

(C) 2018 Published by MECS Publisher. Selection and/or peer review under responsibility of the Research Association of Modern Education and Computer Science.

\section{Introduction}

It is always the main issue to protect the lives of victim peoples and rescue workers in an accident issue and in some cases, they can't get needed help. A new branch of robotics promises to save lives in dangerous situations by placing the risk in the hands of machines instead of rescue personnel. These machines are called as Urban Search and Rescue Robots (USAR).

In our country, there are different kind of natural calamities and man-made disaster happen like earthquake, flooding, hurricane and they cause collapsed the building. During different kinds of disasters, different people are deployed to save lives. They must determine the location and status of victims as quickly as possible.

* Md.Moniruzzaman.

E-mail address: anirz49@gmail.com 
However, most of the time they cannot trace them in time and lots of life is lost. Recovering survivors from a disaster area have proven to be one of the more daunting challenges that face rescue workers in today's world. Survivors trapped in a rubble pile generally have 48 hours before they will the temptation to dehydration and the elements. This is sure will be the pathetic incident if a rescue team couldn't do it in time. In order to solve this problem, our main project is to design and implement a cost-effective Urban Search and Rescue (USAR) robot which will detect the victim and reduce the burden of the rescue mission. A USAR robot should be light weighted, highly mobile, and easy to control. Specifically, the robot was designed to overcome the pre-selected obstacles that represented a sample of the types of impediments found in a disaster area [1].

\section{Historical Background}

In Renaissance Italy, Leonardo da Vinci sketched plans for a humanoid robot around 1495. The first truly modern robot, digitally operated and programmable, was invented by George Devol in 1954 and was ultimately called the Unimate [2].

The first electronic autonomous robots with complex behavior were created by William Grey Walter of the Burden Neurological Institute at Bristol, England in 1948 and 1949. They were named Elmer and Elsie. These robots could sense light and contact with external objects, and use these stimuli to navigate.

The first truly modern robot, digitally operated and programmable, was invented by George Devol in 1954 and was ultimately called the Unimate. Devol sold the first Unimate to General Motors in 1960, and it was installed in 1961 in a plant in Trenton, New Jersey to lift hot pieces of metal from a die casting machine and stack them. Devol's patent for the first digitally operated programmable robotic arm represents the foundation of the modern robotics industry [3]. At the beginning of the 1980s, the idea of search and rescue robots was emerged. However, until the 1990s there weren't any real and practical development in this field. Although robots are not widely used in actual search and rescue situations at that moment of the development in this field seems quite promising and encouraging [4]. The use of USAR robot domain was first introduced by R. Murphy and J. Blitch in Oklahoma City bombing in 1995. After 2001 USAR robots were applied on several occasions like hurricanes effect in Charley, Dennis, Katrina and Wilma, earthquake effect in L'Aquila, Italy [5]. Recently, all over the world took a look at the USAR robot because it can easily minimize the burdens of a rescue mission. At CSU, the USAR senior design group is comprised of eighteen Mechanical Engineers and three Electrical Engineers divided into four teams. The first team is the platform team. The platform teams job is to take the Good Samaritan robot developed by the 2005/2006 senior design group and make structural and electrical improvements to it. The second team is the arm team whose job is to create a functional robotic arm that can be mounted on the 2005/2006 Good Samaritan platform. With a camera mounted on the tip of the arm, the arm allows greater visual feedback to the person driving the robot and can even flip the robot over if it rolls upside down. The third team in the group is the mini team. The mini team's job is to take the 2005/2006 platform and design a roughly half-size version of it while making design improvements in the process. The purpose of the smaller platform is to gain access to locations the larger platform can't fit into. Finally, the last USAR team is the interface team. The interface team's job is to design all of the software that runs both on the remote PC used for control and the computers aboard each robot. They also are in charge of the majority of the sensors used on the platforms and interfacing them to the software [6]. Many universities are researching urban search and rescue robotics, especially in the USA, Japan, and Europe. The University of South Florida developed a robot named CRASAR (Centre for Robot-Assisted Search and Rescue). That is maybe the most advanced project for a search and rescue robot. The aim of this robot is to help the first-aid workers by giving them a picture of a place that they cannot reach. So they can see the environment, see if there are victims, or something else. This robot was used for first time in real conditions on 11th September 2001 in the World Trade Center disaster [7]. Japan Researchers from Japan's Kobe University have several homogeneous small robots that can link together to form a large robot in order to climb large obstacles. Most of their research comes visible to be focused on large-scale coordination efforts such as disaster relief after the Hanshin-Awaji Earthquake that hit Kobe City in 1995. They have also developed a simulator for RoboCup Rescue Simulation 
league emphasizes coordination rather than victim detection and issues individual robots must solve [8]. The University of Tokyo developed snake robots for exploration of small spaces in disaster sites. They are designed so that they can be deconstructed into many parts for transportation to the site though their mobility in a disaster area is somewhat limited. The snake robots are designed only with a camera and microphone and do not seek to detect victims autonomously [9]. Currently, search and rescue robotics is a large and active field in both academic and industrial life. Robots are ideal for when it is dangerous to send in human rescue workers including environments resulting from earthquakes, fires, floods and an unwanted accident like collapsed building, landslide or crater etc [10].

\section{Block Diagram}

Block diagrams give us a better understanding of a system's functions and help create interconnections within it. They are used to describe hardware and software systems as well as to represent processes. Block diagrams are described and defined according to their function and structure as well as their relationship with other blocks. In this way, we can workflows of information and communication among individual components within a large system. A graphical representation is often easier to understand than a textual representation. See Fig 1.
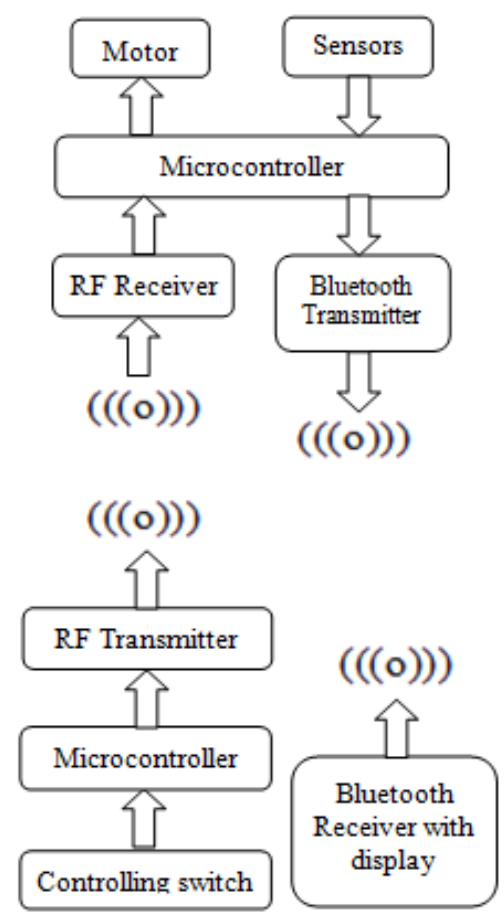

Fig.1. Block Diagram of USAR Robot

\section{Mechanical Construction}

Mechanical assembly of the 4WD (4 wheel drive) with a metal chassis has several parts of the construction. Because of their high degree of manoeuvre ability, four-wheel steered robotic vehicles have increasingly attracted interest in many applications. These robots are characterized by the ability to easily manoeuvre tight turns. 


\subsection{Structure Body/chassis Assembly}

A frame of metal sheet provides the base of the robot and lends its support to operate in rough condition. The box frame is particularly well suited for robots that require support for heavy components. It will prevent the damage to internal circuits, sensors, and other components. Mounting hub and metal clamp were used to set the wheel and gear motor with the metal body. See Fig 2.
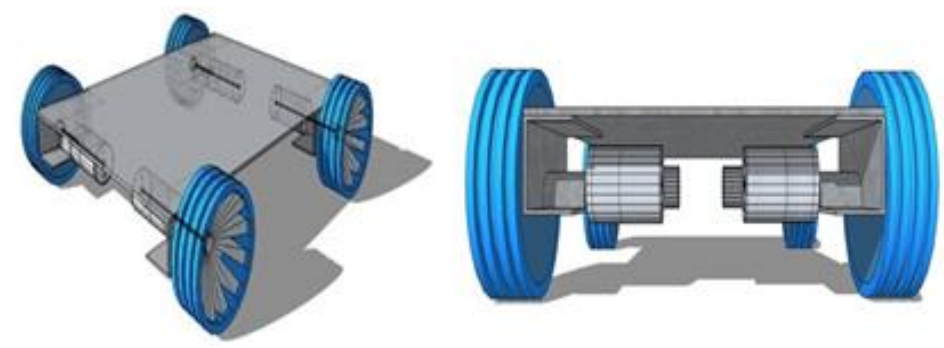

Fig.2. (a) Diagonal view of USAR Robot; (b) Front view of USAR Robot

\subsection{Motor and Wheel Assembly}

12-volt de gear motor used to generate high torque to carry the total robot's load and can run smoothly on a rough surface. Motors are attached to each of the side plates of chassis with metal clamp and screw. Wheels are attached to the motor shaft with the mounting hub and screw. In order to avoid wheel slippage and climb over the rough surface during mobile robot navigation, lightweight plastic wheels are mounted with tires See Fig.3.
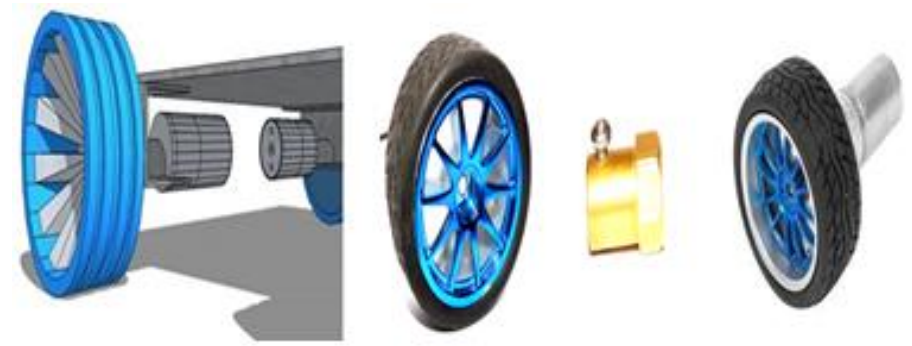

Fig.3. (a) Motor mounted with body; (b) Wheel mounted with motor

\section{Simulation}

The simulation represents the key characteristics or behaviors of the selected system. There are various kinds of simulating software for different kind of works. The PROTEUS simulator is used for the simulation of the Urban Search and Rescue robot (USAR). Proteus Simulator is one of the best and most popular simulators. The Proteus simulator is used to simulate the microprocessor, the motor driver, and PIR sensor and carbon dioxide sensor. After getting the desired simulation result the hardware part of the robot is constructed. Fig. 4 shows the simulation of the Urban Search and Rescue Robot[11]. 


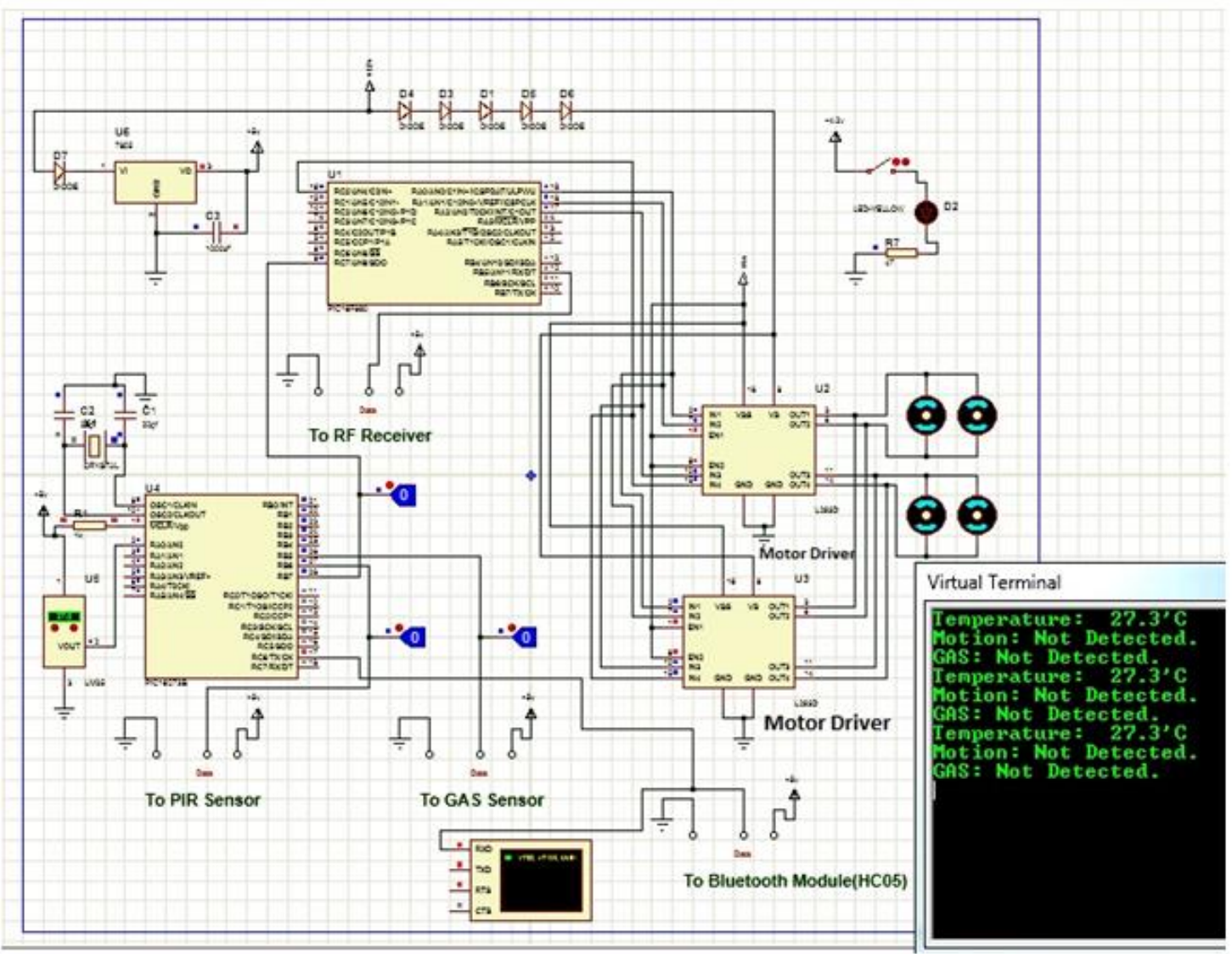

Fig.4. Simulation of USAR Robot

\subsection{Motor Driver}

In this simulation two Motor driver IC and Microcontroller are used to control the movement of urban search and rescue robot in any direction. This two motor driver ICs are connected in parallel with DC Motors to reduce overheating for high operating current.

Those ICs are operated by the Microcontroller in robot unit. This Microcontroller receives the wireless signal through RF receiver from the robot receiving the part. The microcontroller gives the instruction to the motor driver depending on the specific bits of the receiving signal to move the robot Forward, Backward, Left or Right [12].

\subsection{RF Transmitter and Receiver}

RF Module is used for transmitting and receive information. The RF transmitter is connected to the microcontroller in controller unit. When push button pressed from the remote control, microcontroller sense the change and microcontroller will generate a specified bit configuration. This data contains 8-bit address bit and 4-bit data bit. This 12 bit data will serially send into RF transmitter module (JMR-TX-1). On the other hand, the RF receiver module (RFB6) will receive the serial data which is sent from RF transmitter module. This data will send to the microcontroller in robot unite to control [13]. RF data communication is shown in Fig.5. 


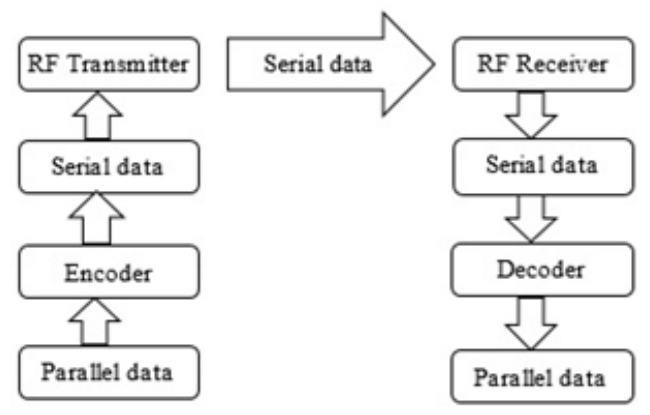

Fig.5. Flowchart of RF data communication

\subsection{PIR sensor}

A Passive Infrared Sensor is connected to the robot unit with the microcontroller. When anything moves in front of the sensor it creates a high pulse and sends it to the microcontroller. After receiving the signal from PIR sensor microcontroller in robot unit send information to the user through Bluetooth module.

\subsection{Co2 Gas Sensor Module}

A Gas sensor (Carbon dioxide) is connected to the microcontroller in robot unit. A push switch is used to control the power supply of the carbon dioxide sensor. It allows a microcontroller to determine the present Carbon Dioxide gas level has been reached or exceeded.

\subsection{Bluetooth Module}

Bluetooth Module is used for transmitting information. Bluetooth Module is connected to the microcontroller in robot unit. When the switch is pressed from the remote control microcontroller sense the change and microcontroller will generate a specified bit configuration and transmit the data to another Bluetooth device with the display or any a Bluetooth mobile apps display. The microcontroller is coded to check when a specific switch is pressed from the remote control, microcontroller senses the change and transmits the data.

\section{Hardware Implementation}

The microcontroller is coded to check push buttons continuously and when any switch is pressed microcontroller sense the change and send data through RF Transmitter which is also connected to a microcontroller in controller unit [14]. Two Motor driver IC and microcontroller in robot unit were used to control the movement of urban search and rescue robot in any direction. This two L293D motor driver ICs are connected in parallel with DC Motors to reduce overheating for high operating current. Those ICs are operated by the Microcontroller PIC16F690. This Microcontroller receives the signal from the remote controller part through RF receiver. The microcontroller gives the instruction to the motor driver depending on the specific bits of the receiving signal from RF transmitter remote controller part to move the robot Forward, Backward, Left or Right. See Fig.6. 

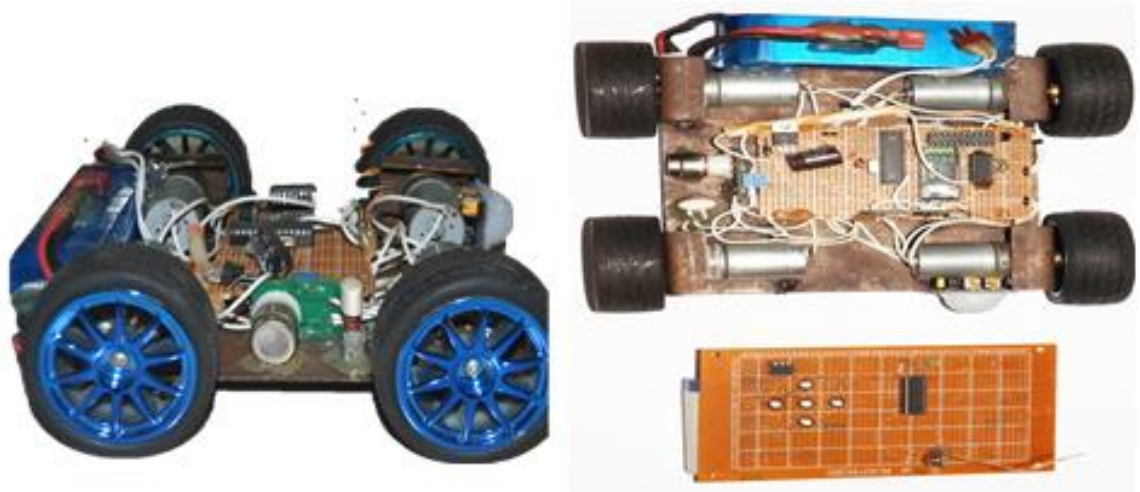

Fig.6. (a) Right view of implemented of USAR Robot; (b) Right view of implemented of USAR Robot

Portable Master Bluetooth device with Display (Android mobile with apps) is used to get the status of temperature, human movements, and $\mathrm{CO}_{2}$ level through a temperature sensor, PIR motion sensor, $\mathrm{CO}_{2}$ gas sensor through Bluetooth module [14].

\section{Discussion and Conclusion}

This urban search and rescue robot is a combination of mechanical, electrical and electronic elements. We have tried to design our robot by using advanced robotic technology. Throughout this project, we have learned several new technologies and ways to operate them.

Before implementation, both the electrical and the mechanical parts were investigated thoroughly using virtual tools. The electrical parts were simulated using "Proteus" and the mechanical parts were designed using "AutoCAD". After successful virtual simulation, we proceeded on to the hardware implementation.

Especially we faced some major problem while implementing the robot physically. The main challenge was to build our robot small, light and strong but we faced a lot of difficulties when tried to combine them. The robot had to carry the battery, camera, gear motor and circuit boards. These components required a lot of space and forced us to change our design several times. Battery and gear motor took most of the space of the robot.

We used rubber wheel for more friction on the surface. Metal Wheel rim was not available in the local market, so we had to use a plastic rim. Our robot was unable to climb concrete, so we had to change gear motor contained more torque. Even in the electrical portion, we faced several problems. Some components were not readily available while some available components were found faulty after purchasing. We tried to make wireless communication with RF module only, but due to the same channel of two RF module and overlapping of their frequencies, we had to use one RF module and one Bluetooth module. We used RF module to control the robot and Bluetooth module to get information from robot

\section{References}

[1] Choset Howard, "Search and Rescue," [Online] (Accessed on 10.01.2014). Available:http://www.ri.cmu. edu/projects/project_407.html

[2] “Leonardo da Vinci's Robots”.Leonardo3.net.Retrieved 2008-09-25.

[3] Owen Holland the Grey Walter Online Archive. Retrieved 2008-09-25

[4] All on robots website, [Online] (Accessed on 10.05.2014). Available: http://www.allonrobots.com/rescuerobots.html 
[5] Slide share website, [Online] (Accessed on 18.02.2014). Available: http://www.slideshare.net/amirhst/ urban-search-and-rescue-usar-robotics.

[6] RoboCup 2007 - Atlanta [Online] (Accessed on 20.03.2014). Available: http://www.robocup-us.org.

[7] J. Casper "Human-Robot Interactions during the robot-assisted urban search and rescue response At the world trade center", MS Thesis, Computer Science, and Engineering, USF, South Florida, 2002.

[8] UVS Project (Japan): [Online] (Accessed on 06.06.2014). Available: http://www.r.cs.kobe-u.ac.jp/uvs/ [9] Tokyo University: [Online] (Accessed
Available:http://www.titech.ac.jp/publications/e/publications.html on $\quad 05.02 .2014)$.

[10] S. Burion, "Human Detection for Robotic Urban Search and Rescue," master's thesis, Robotics Inst., Carnegie Mellon University, 2004; [Online] (Accessed on 10.01.2014)

[11] ASM Shamim Hasan, Md. Khalid Hossain Jewel, Md. Niaz Mostakim, Nabil Hossain Bhuiyan, M.K. Rahman, Sheikh Dobir Hossain, Md. Khalid Hossain,"Smartphone Controlled Spy Robot with Video Transmission and Object Collector", International Journal of Engineering and Manufacturing(IJEM), Vol.7, No.6, pp.50-58, 2017.DOI: 10.5815/ijem.2017.06.05

[12] Thanet Ketthong, Satean Tunyasirut, Deacha Puangdownreong, "Design and Implementation of I-PD Controller for DC Motor Speed Control System by Adaptive Tabu Search", International Journal of Intelligent Systems and Applications (IJISA), Vol.9, No.9, pp.69-78, 2017. DOI: 10.5815/ijisa.2017.09.08

[13] Weidong Zhang,Gengsheng Zheng,Qifu Liu,"Circuit Design of RF Remote Controller in Code Matching Mode", International Journal of Engineering and Manufacturing(IJEM), Vol.1, No.4, pp.13-19, 2017.DOI: 10.5815/ijem.2011.04.03

[14] Nureni A. Yekini., Adetokunbo O. Oloyede, Akinwole K. Agnes, Folasade M.Okikiola,"MicrocontrollerBased Automobile Tracking System with Audio Surveillance using GPS and GSM Module", International Journal of Information Engineering and Electronic Business(IJIEEB), Vol.8, No.3, pp.41-46, 2016. DOI: $10.5815 /$ ijieeb.2016.03.05

\section{Authors' Profiles}

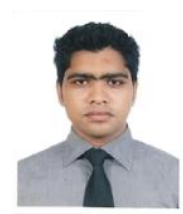

Md. Moniruzzaman (born February 5, 1992) completed his BSc. In EEE from American International University- Bangladesh. Later, he joined as a Research Engineer in ARMS Bangladesh Ltd where he is working on prototypes and system development and commercialize products and technologies.

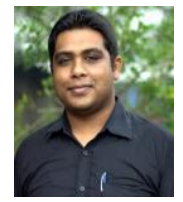

Md. Saniat Rahman Zishan is a Senior Assistant Professor at the Department of EEE \& CoE in American International university Bangladesh (AIUB). He is enrolled for $\mathrm{PhD}$ degree at Universiti Sultan Zainal Abidin, Malaysia. He completed his M.Engg. in Telecommunication and B.Sc. in Electrical and Electronic engineering both from AIUB. His research interests are in the field of telemedicine, wireless communication, signal processing, Robotics, Adhoc Network etc.

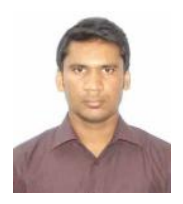

Sabbir Rahman completed his BSc. In EEE from American International UniversityBangladesh. His research interest are intelligent systems design. 
Sanwar mahmud completed his BSc. In EEE from American International UniversityBangladesh. His interest on robotics and embedded system.

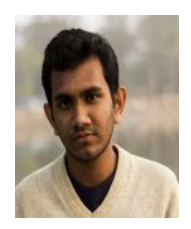

Antar Shaha completed his BSc. In EEE from American International University- Bangladesh. Area of interest in microprocessor-based project.

How to cite this paper: Md. Moniruzzaman, Md. Saniat Rahman Zishan, Sabbir Rahman, Sanwar Mahmud, Antar Shaha,"Design and Implementation of Urban Search and Rescue Robot", International Journal of Engineering and Manufacturing(IJEM), Vol.8, No.2, pp.12-20, 2018.DOI: 10.5815/ijem.2018.02.02 